\title{
Does Pride Have a Recognizable Expression?
}

\author{
JESSICA L. TRACY AND RICHARD W. ROBINS \\ Department of Psychology, University of California-Davis,
} Davis, California 95616-8686, USA

KEYWORDS: pride; expression; emotion

In 1872, Darwin speculated that emotion expressions in humans and animals are evolved products of natural selection. He argued that a number of emotion expressions are universal, and he wrote, "Of all the ... complex emotions, pride, perhaps, is the most plainly expressed. A proud man exhibits his sense of superiority over others by holding his head and body erect ... and makes himself appear as large as possible" (p. 263). ${ }^{1}$

Although contemporary emotion researchers have supported Darwin's general speculation by identifying discrete, universally recognized facial expressions for a small set of "basic" emotions (e.g., ref. 2), they have not found a distinct nonverbal expression for pride. In fact, because happiness is the only positively valenced emotion thought to have a discrete, nonverbal expression, researchers have concluded that all positive emotions share the same expression. ${ }^{3,4}$ The finding that pride has a unique, identifiable expression would challenge this assumption, suggest that pride meets a central criterion for biologically based emotions, and imply that pride may have evolved to serve a particular communicative function-possibly to convey success and thereby promote status and dominance.

In this paper, we summarize findings from five studies that test whether pride has a distinct, recognizable, behaviorally visible expression (see FIG. 1). In study 1, 56 judges viewed photographs of male and female targets posing expressions of happiness, pride, and surprise and were asked to identify the emotion expressed in each photo. Judges chose from these options: "happiness," "pride," "surprise," and "no emotion." The results show that

Address for correspondence: Jessica L. Tracy, University of California, Department of Psychology, Davis, CA 95616-8686. Voice: 530-754-8299; fax: 530-752-2087.

jltracy@ucdavis.edu

Ann. N.Y. Acad. Sci. 1000: 1-3 (2003). ( 2003 New York Academy of Sciences. doi: 10.1196/annals.1280.001

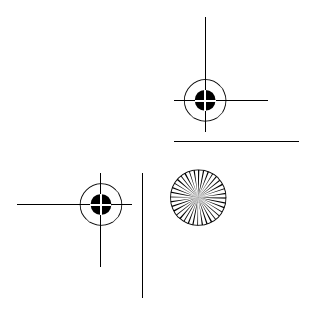




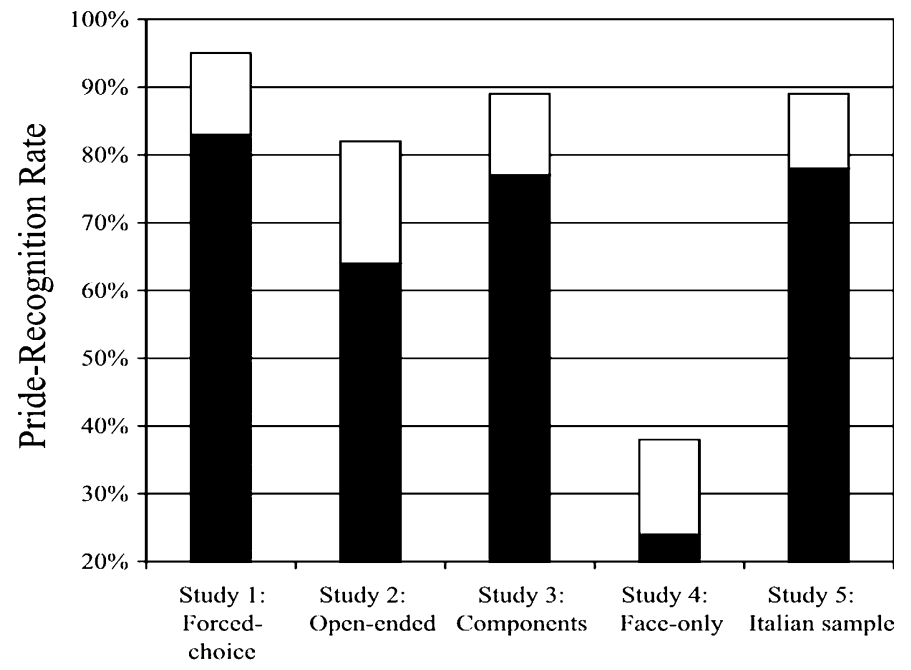

FIGURE 1. Pride recognition rates for studies 1-5. The black bars show mean recognition rates across pride photos; the white bars show recognition rates for the best pride photo. Studies 1, 3, 4, and 5 used a forced-choice response format (judges were given 4 response options in study 1 and 8 response options in studies 3-5). Recognition rates in studies $1,2,3$, and 5 are comparable to those found for basic emotions in the present research and in previous studies.

judges agreed on a pride expression and could distinguish pride from both happiness and surprise.

In study 2, 96 judges responded to the photos using an open-ended response format. This design addresses a potential critique of study 1 -namely, that the forced-choice response format may constrain judges' response options and thereby inflate recognition rates. ${ }^{5} \mathrm{~A}$ set of coders rated the extent to which each open-ended response was prototypical of pride. Results showed that responses to the pride photos were classified as prototypical of pride at frequencies that were greater than chance and comparable to those found in previous open-ended studies of basic emotions. ${ }^{6}$

In study $3(N=178)$, we manipulated several facial and bodily features to more precisely determine the components of the pride expression. Results showed that the pride expression includes a small smile, head tilted slightly back, arms either raised above the head or hands placed on the hips, and a visibly expanded posture.

In study 4, 85 judges viewed photos cropped to include only the face. Pride recognition was below chance for all face-only photos, suggesting that, unlike basic emotions, the pride expression includes more than the face. 
Finally, in study 5, 28 judges who were born, raised, and living in Italy viewed the photos. Pride recognition rates were comparable to recognition rates for United States judges, suggesting that the pride expression generalizes at least across Western cultures.

In summary, these studies show that pride has a recognizable nonverbal expression, which can be distinguished from expressions of other positive emotions and can be identified using forced-choice and open-ended response formats. The expression is recognized equally well by men and women and by American and Italian judges. These findings imply that pride can be added to the pantheon of emotions that have discrete behavioral expressions, that pride might have evolved to serve communicative functions, that nonverbal expressions of emotion are not restricted to the face, and that it might be possible to assess pride from nonverbal behaviors.

\section{REFERENCES}

1. Darwin, C. 1872. The Expression of the Emotions in Man and Animals, 3rd edit. P. Ekman, Ed. Harper Collins. London. (US edit.: Oxford University Press. New York).

2. Ekman, P., E.R. SOREnSON \& W.V. Friesen. 1969. Pan-cultural elements in facial displays of emotion. Science 164: 86-88.

3. Ekman, P. 1992. An argument for basic emotions. Cognit. Emotion 6: 169200.

4. Fredrickson, B.L. \& C. Branigan. 2001. Positive emotions. In Emotions: Current Issues and Future Directions. T.J. Mayne \& G.A. Bonanno, Eds.: 123-151. Guilford Press. New York.

5. Russell, J.A. 1994. Is there universal recognition of emotion from facial expressions? A review of the cross-cultural studies. Psychol. Bull. 115: 102141.

6. Boucher, J.D. \& G.E. Carlson. 1980. Recognition of facial expression in three cultures. J. Cross-Cult. Psychol. 11: 263-280. 